\title{
ANALISIS PEMBANGKIT 3 FASA DENGAN VIRTUAL INSTRUMENT
}

\author{
Ahmad Ramadhan \\ Prodi TeknikElektro UNPAM \\ Jln. Puspiptek Raya No 46 Buaran, Setu - Tangerang Selatan 15310 INDONESIA \\ Email:dosen00858@unpam.ac.id
}

\begin{abstract}
ABSTRAK
Pengembangan peralatan model praktikum saat ini telah banyak dilakukan, hal ini diperlukan guna mempermudah dalam kegiatan praktikum.Peralatan praktikum sebelumnya masih mengunakan sistem yang konvensional, banyak digunakan peralatan pendukung untuk melakukan suatu model praktikum tersebut.Maka diperlukan pengembangan model praktikum menggunakan perangkat Virtual Instrument yang bertujuan untuk mempermudah melakukan kegiatan praktikum.Metode praktikum dengan Virtual instrumentadalah membuat perangkat yang dapat melakukan pengukuran secara lebih akurat, adapun perangkat yang digunakan berupa NI MyDAQ sebagai hardware dan LabView sebagai software. Hasil yang diperoleh dari praktikum dengan Virtual Instrument adalah dapat lebih mudah dalam mendapatkan data pengukuran dan mudah untuk dioperasikan.Berdasarkan hasil yang telah diperoleh, didapat kesimpulan praktikum dengan menggunakan Virtual Instrument mempermudah kegiatan praktikum, lebih sedikit peralatan yang digunakan dan dapat diatur data apa saja yang akan diperoleh.
\end{abstract}

Kata kunci :Pengukuran, labview, NI MyDAQ,

\begin{abstract}
Development of practicum model equipment currently has been carried out, this is needed to facilitate practical work. Previous practicum equipment still uses a conventional system, a lot of supporting equipment is used to conduct a practicum model.So it is necessary to develop a practicum model using a Virtual Instrument device which aims to facilitate practicum activities. The practicum method with Virtual instrument is making a device that can make measurements more accurately, while the device used is the MyDAQ NI as hardware and LabView as software. The results obtained from the practicum with Virtual Instrument are easier to obtain measurement data and are easy to operate. Based on the results that have been obtained, a practical conclusion is obtained by using Virtual Instrument to facilitate practicum activities, less equipment is used and can be arranged what data will be obtained.
\end{abstract}

Keywords: Measurement, labview, NI MyDAQ. 


\section{PENDAHULUAN}

Kemajuan teknologi sudah menyentuh disegala sisi kehidupan masyarakat. Orang akan selalu berusaha mendapatkan hal-hal yang bersifat lebih praktis, hemat efisien, dan berdaya guna tinggi. Segala macam permasalahan pada masa lalu yang rasanya tidak mungkin terjadi, untuk saat sekarang mungkin saja terjadi.Begitupun dengan kemjuan teknologi di dunia pendidikan, dalam hal ini kegiatan praktikum.Banyak pengembangan yang dilakukan guna memperoleh kemudahan.

Sinyal digital merupakan hasil kemajuan teknologi yang dapat mengubah signal menjadi kombinasi urutan bilangan 0 dan 1 (biner), sehingga tidak mudah terpengaruh oleh derau, proses informasinya pun mudah, cepat dan akurat, tetapi transmisi dengan isyarat digital hanya mencapai jarak jangkau pengiriman data yang relatif dekat. Biasanya isyarat ini juga dikenal dengan isyarat diskret. Sinyal yang mempunyai dua keadaan ini biasa disebut dengan bit. Bit merupakan istilah khas pada isyarat digital. Sebuah bit dapat berupa nol (0) atau satu (1).
Kemungkinan nilai untuk sebuah bit adalah 2 buah $\left(2^{1}\right)$. Kemungkinan nilai untuk 2 bit adalah sebanyak $4\left(2^{2}\right)$, berupa 00, 01, 10, dan 11. Secara umum, jumlah kemungkinan nilai yang terbentuk oleh kombinasi $\mathrm{n}$ bit adalah sebesar $2 n$ buah.

Salah satu rangkaian yang dapat membangkitkan sinyal digital adalah rangkaian Flip-Flop (FF) dalam Multivibrator. Rangkaian Flip-Flop (FF) merupakan suatu rangkaian yang terdiri dari dua elemen aktif yang bekerja secara bergantian. Rangkaian ini berfungsi sebagai pencacah pulsa, menyimpan bilangan biner, dan mensinkronisasikan suatu rangkaian aritmatika. Pemahaman terhadap rangkaian Flip-Flop (FF) ini sangat penting karena Flip-Flop (FF) merupakan satu sel memori. Keadaan keluaran FlipFlop (FF) dapat berada dalam keadaan tinggi atau keadaan rendah, untuk selang waktu yang dikehendaki. Biasanya untuk mengubah keadaan tersebut diperlukan suatu masukan pemicu. Sebuah FlipFlop (FF) mempunyai input pengendali (triggering), yang disebut dengan input waktu (clock), yang mampu melakukan 
sinkronisasi perubahan dua keadaan tersebut dengan pulsa waktu. Flip-Flop (FF) dapat mengubah keadaan pada sisi positif atau negatif dari pulsa waktu. Teknik sinkronisasi ini disebut dengan edge-triggering.

Berdasarkan uraian diatas, maka dilakukan penelitian tentang pembangkit sinyal digital. Dalam penelitian ini akan dianalisa pembangkit sinyal digital 3 fasa dengan menggunakan virtual instrument $\mathrm{NI}$ MyDAQ, dengan Virtual Instrument kegiatan praktikum dapat lebih mudah dilakukan dan hasil data pengukuran lebih cepat didapat.

\section{LANDASAN TEORI}

Flip-Flop adalah suatu rangkaian digital yang sangat sederhana yang berfungsi sebagai memori untuk 1 bit atau disebut juga latch. Rangkaian latch terdiri dari dua buah gerbang NOT (gerbang NAND masukan tunggal) G1 dan G2, keluaran dari suatu gerbang diumpan balikkan ke masukan pada gerbangyang lain. Kombinasi umpan balik ini disebut flip-flop. Sifat penting yang dimiliki flip-flop adalah flip-flop tersebut hanya mempunyai dua keadaan stabil $\left(Q=1, Q^{\prime}=\right.$ 0 , dan $Q=0$, dan $Q^{\prime}=1$ ). Sebagai contoh, jika keluaran dari $\mathrm{G} 1$ adalah $\mathrm{Q}=1$, maka $\mathrm{B}$, masukan ke G2 juga pada logika 1. Gerbang G2, yang berfungsi sebagai pembalik, akan menghasilkan keluaran Q' pada logika
0.Karena Q' dihubungkan ke A, maka masukan ke G1 juga 0, dan keluaran $Q$ pada logika 1 , yang sesuai dengan keadaan awal. Maka $Q=1, Q^{\prime}=0$ merupakan salah satu kemungkinan keadaan stabil. Dengan cara yang sama dapat dibuktikan bahwa $Q=0, Q$ ' $=1$ juga merupakan keadaan stabil yang lain. Tetapi, Q dan Q' tidak mungkin mempunyai keadaan yang sama (keduanya pada logika 1 atau logika 0 ).

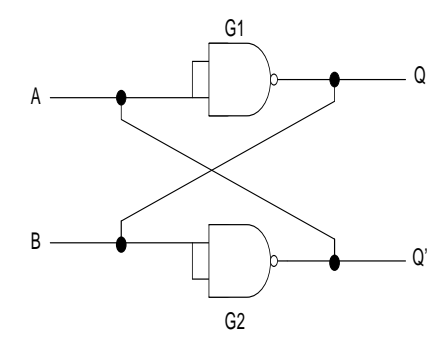

Gambar 2.1 Flip-flop dasar atau latch

Dari keadaan diatas jelaslah bahwa flip-flop hanya mempunyai dua keadaan stabil, sehingga sering disebut sebagai untai biner atau untai bistabil (bistable circuit). Selain itu, karena flip-flop menyimpan satu bit informasi $(Q=0$ atau $Q=1)$, maka flipflop disebut sebagai satuan memori satu bit atau sel. Lebih lanjut, karena informasi tersebut terkunci di dalamnya, maka dalam hal ini flip-flop bertindak sebagai sebuah latch.

\section{Flip - Flop Tipe $D$}

S-R terdetak dapat dimodifikasi seperti terlihat pada Gambar 2.2 untuk menambahkan tunda satu bit pada sebuah jalur data masukan, D. Sebuah pembalik ditambahkan pada masukan $R$ sehingga masukan $\mathrm{R}$ merupakan koplemen dari 
masukan S. Dalam keadaan ini, flip-flop selalu berada pada keadaan $\mathrm{D}=1$ (set) atau $\mathrm{D}=0$ (reset). Pada dasarnya untai adalah sebuah flip-flop $S-R$ dengan keadaan $S=R$ = 1 yang dihilangkan, karena keadaan ini tidak akan pernah terjadi lagi. Demikian juga halnya keadaan $S=R=0$ juga tidak mungkin terjadi. Tabel 2.1 menunjukkan tabel kebenarannya. Untai akan berfungsi dengan datangnya sebuah pulsa detak. Keluaran $\left(Q_{n+1}\right)$ selama selang waktu $t_{n+1}$ adalah keadaan logika masukan (Dn) selama selang waktu sebelumnya $\left(t_{n}\right)$. Dengan demikian, tunda waktu satu bit diperoleh untuk semua data masukan. Flipflop tipe $D$ sangat berguna untuk pengiriman data dari satu piranti ke piranti lain, misalnya dari memori ke register dimana flip-flop tipe D digunakan untuk setiap bit seperti terlihat pada Gambar 2.4. Bit-bit masukan ditempatkan pada jalur $D$ oleh piranti masukan, dan dengan datangnya pulsa detak, masukan akan ditransfer ke keluaran $Q_{0}-Q_{3}$ dan ke piranti kedua. Setelah pulsa detak memicu gerbang masukan dari flipflop, segala perubahan keadaan dari masukan tidak akan berpengaruh pada keluraran. Sehingga interval waktu $t_{n}$ diantara pulsa detak tersedia untuk menempatkan data berikutnya pada jalur $D$.

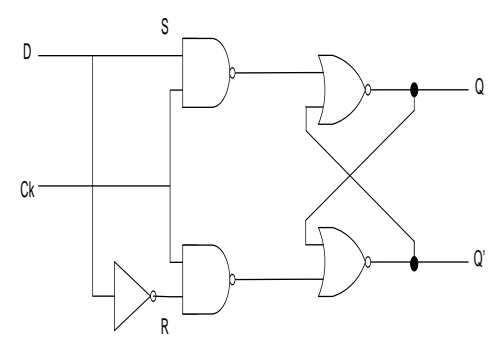

Gambar 2.2 Flip-flop tipe D

Tabel 2.1 Tabel kebenaran D flip-flop

\begin{tabular}{|l|l|l|}
\hline Detak & Dn $\left(t_{n)}\right.$ & $Q_{n+1}\left(t_{n+1}\right)$ \\
\hline 0 & $X$ & Tetap \\
1 & 0 & 0 \\
1 & 1 & 1 \\
\hline
\end{tabular}

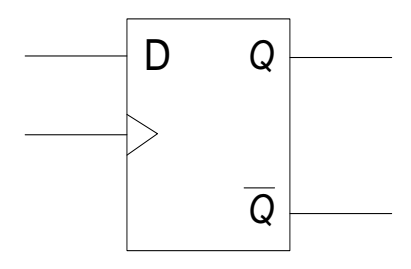

Gambar 2.3 Simbol Flip-flop

\section{Pengertian Multivibrator}

Multivibrator merupakan osilator, sedangkan osilator adalah rangkaian elektronika yang menghasilkan perubahan keadaan pada sinyal output.Osilator dapat menghasilkan clock/sinyal pewaktu untuk sistem digital seperti komputer.Osilator juga bisa menghasilkan frekuensi dari pemancar dan penerima radio.

Multivibrator adalah suatu rangkaian yang terdiri dari dua buah piranti aktif dengan keluaran yang saling berhubungan dengan masukan yang lain. Umpan balik positif yang dihasilkan menyebabkan piranti yang satu harus di cut off, sedangkan piranti 
yang lain dipaksa melakukan penghantaran. Multivibrator dikelompokkan kedalam bistabil, monostabil, dan astabil.Rangkaian multivibrator bistabil memiliki ciri-ciri, rangkaian ini tetap berada pada tingkatan (level) keluaran yang diberikan apabila tidak dikenakan sinyal (trigger) dari luar. Penerapan sinyal dari luar akan menyebabkan perubahan keadaan, dan tingkat keluaran ini akan tetap sampai ada sinyal dari luar berikutnya. Jadi rangkaian bistabil memerlukan dua sinyal sebelum kembali kekeadaan awal.Multivibrator monostabil atau one shot, menghasilkan satu pulsa dengan selang waktu tertentu dalam menanggapi suatu sinyal trigger dari luar.Ini berarti bahwa hanya satu saja keadaan stabil. Penerapan trigger mengakibatkan perubahan keadaan kuasi stabil, yang berarti bahwa rangkaian tetap berada pada keadaan kuasi stabil pada selang waktu yang ditentukan dan kemudian kembali kekeadaan awal. Akibatnya adalah sinyal trigger internal dibangkitkan yang menghasilkan transisi keadaan stabil.

Multivibrator astabil atau free running adalah multivibrator yang memiliki du keadaan kuasi stabil ( bukan keadaan stabil ), dan kondisi rangkaian berisolasi diantaranya. Dalam hal ini tidak diperlukan sinyal trigger dari luar untuk menghasilkan perubahan keadaan. Karena sifat osilasi diantara dua keadaan ini, rangkaian astabil digunakan untuk menghasilkan gelombang segi empat.

\section{METODOLOGI PENELITIAN}

Metode yang dilakukan dalam penelitian ini adalah membuat rancangan peralatan praktikum menggunakan perangkat Virtual Instrument. Tahapan metode perlu diperhatikan dengan baik, perancangan yang baik dan sistematis akan memberikan kemudahan dalam proses penyelesaianpembuatan alat. Perancangan alat ini mempunyai tujuan, yaitu untuk mendapatkan suatu alat atau sistem yang lebih baik dan seperti yang diharapkan.

\section{Blok Diagram Rangkaian Pembangkit Sinyal}

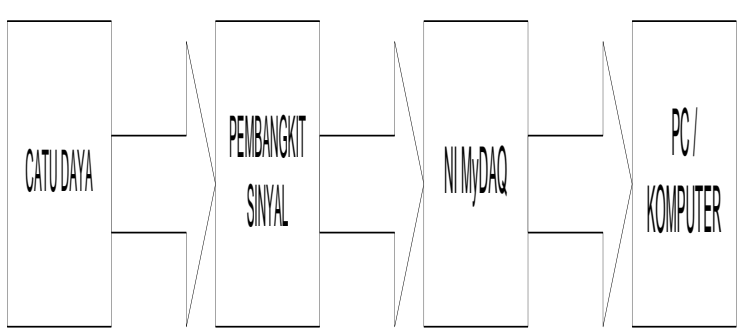

Gambar 3.1. Blok diagram rangkaian pembangkit sinyal.

Blok diagram diatas menunjukan bahwa catu daya mengeluarkan tegangan sebesar 5 VDC, yang kemudian dijadikan tegangan masukan dari pembangkit sinyal. Pada rangkaian pembangkit sinyal, tegangan masukan berfungsi untuk mengoperasikan pewaktu atau clock dan D Flip-flop.Keluaran dari rangkaian pembangit sinyal diukur dan dianalisa dengan $\mathrm{NI}$ MyDAQ, hasil dari pengukuran dan analisa tersebut disimpan dan ditampilkan pada pc / komputer.

\section{Diagram Alir Pengujian Ragkaian}

Dari diagram alir disamping dapat diperhatikan bahwa permulaan pengujian 
rangkaian ini dimulai dari menyiapkan alat dan bahan yang akan dibutuhkan, seperti IC, kapasitor dan variabel resistor. Alat dan bahan tersebut digunakan untuk membangun rangkaian pembangkit sinyal digital. Selain membangun rangkaian sesuai dengan gambar, dilakukan juga pembuatan program LabView berupa blok diagram sebagai analisis rangkaian yang dibuat dan front panel sebagai antar muka yang ditampilkan pada monitor komputer.

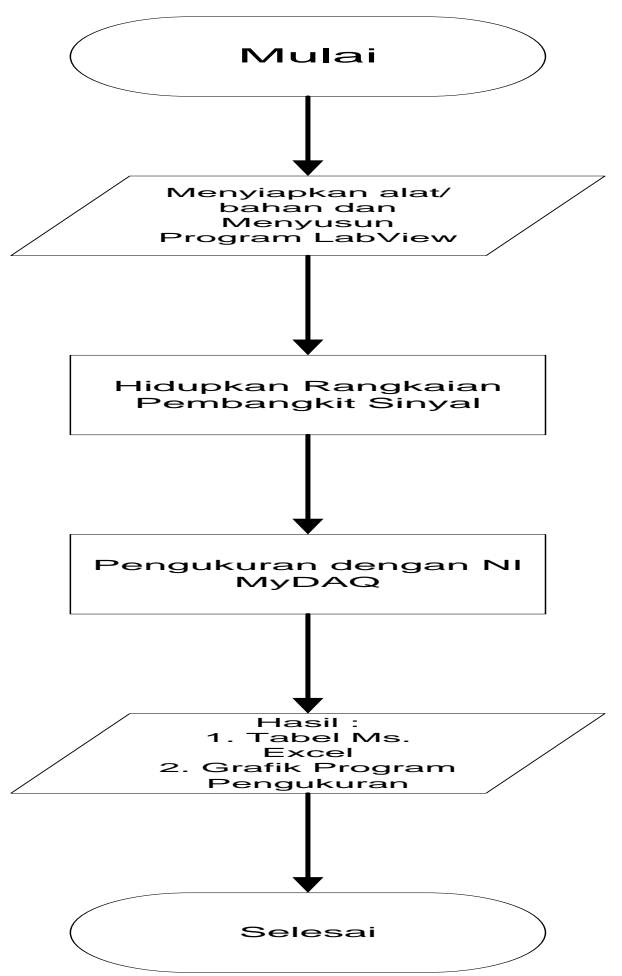

Gambar 3.2. Diagram alir pengujian rangkaian

Hidupkan rangkaian tersebut dan lakukan pengukuran berupa analisa kerja dari rangkaian pembangkit sinyal. Hasil analisa rangkaian tersebut dapat dituangkan dalam grafik sinyal digital dan dapat pula berupa kumpulan bilangan yang dimasukan dalam Ms. Excel. Setelah semua grafik dan data didapat, rangkaian dapat dimatikan dengan begitu semua selasai.

\section{Alat dan Bahan} terdiri dari :

Alat dan bahan pada penelitian ini

\section{Alat pengukuran dengan NI MyDAQ}

$M y D A Q$ merupakan alat ukur yang dikeluarkan oleh National Instrument. Pada alat ukur $M y D A Q$ mempunyai kelebihan di bandingkan dengan alat ukur diatas, dikarena hasil pengukuran dapat ditampilkan dikomputer dan disimpan dalam bentuk File.

\section{Bahan Penelitian}

Pada penelitian ini, bahan yang digunakan untuk pengukuran sinyal digital yaitu :
a. Catu daya dengan output 5 VDC
b. IC digital 7400
c. IC digital 7474
d. IC digital 555
e. kapasitor 10uF/50V.
f. Resistor $10 \mathrm{k} \Omega$
g. Variabel Resistor $100 \mathrm{k} \Omega$
h. Papan Circuit Board (PCB)

\section{Pembuatan Antar Muka Dengan}

\section{Komputer}

Agar mempermudah dalam pengukuran dan analisa rangkaian, digunakan software LabView dan alat instrument yaitu NI MyDAQ,dengan desain antar muka pada komputer. 


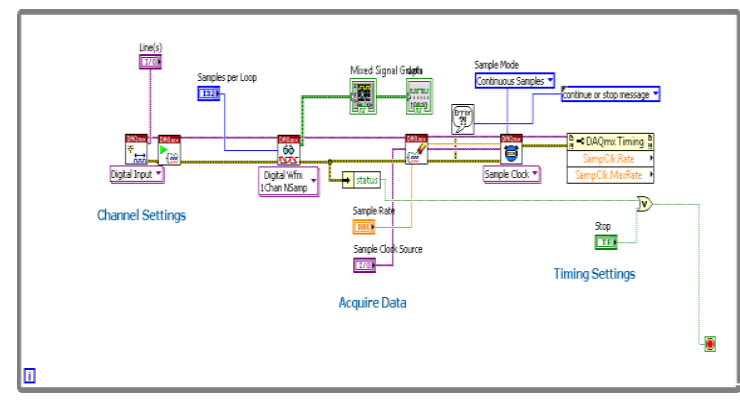

Gambar 3.3 Block diagram pembangkit 3 fasa

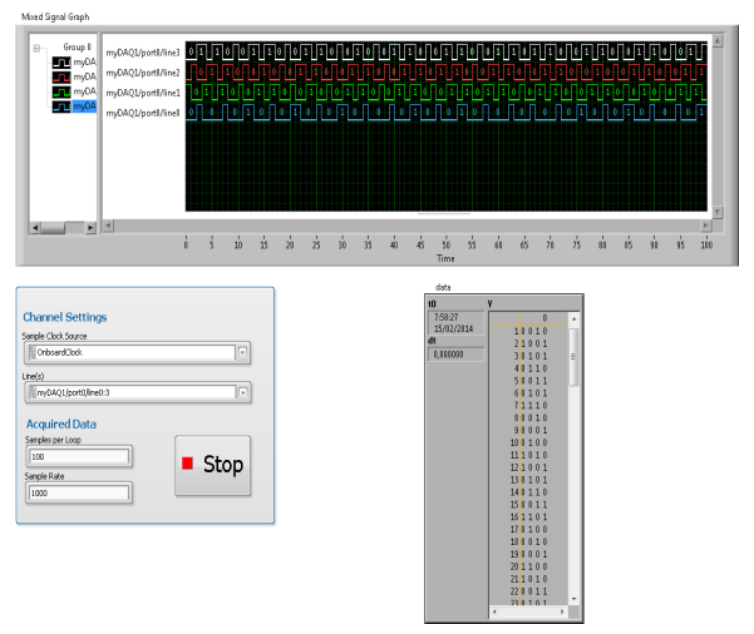

Gambar 3.4. Front panel Pembangkit 3 fasa

\section{Pembuatan Rangkaian pembangkit sinyal}

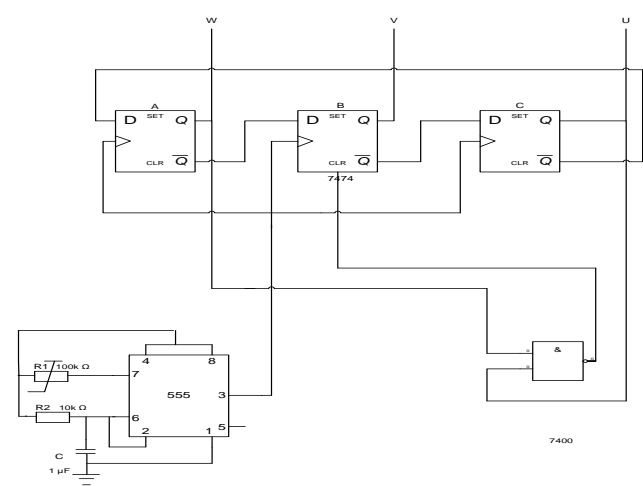

Gambar 3.5 Rangkaian Pembangkit 3 fasa secara digital

Prinsip kerja dari rangkaian diatas dimulai dari pembangkit pulsa yang didapatkan dari rangkaian gerbang NAND (N1, N2, N3) yang hasilnya diumpankan pada D-flip-flop (A, B, C) yang dapat membentuk sebuah penghitung melingkar (ring counter) pada keluaran D-flip-flop. Masing-masing dari keluaran D-flip-flop tersebut saling bergeser yang terhubung melalui keluaran Q̄, dimana masukan dari gerbang NAND (N4) diperoleh dari output $\mathrm{W}$ dan $\mathrm{U}$.

\section{HASIL DAN PEMBAHASAN}

\section{Peralatan Pengujian}

Peralatan yang digunakan dalam pengujian ini adalah MyDAQ dari National Instrument.MyDAQ merupakan suatu perangkat data akuisisi yang digunakan untuk mengukur dan menganalisa sinyal digital.

\section{Hasil Pengukuran.}

Pengukuran pembangkit 3 fasa dengan $\mathrm{Vr}$ $=\mathbf{3 0} \mathrm{k} \Omega$

Pada pengukuran pembangkit 3 fasa secara digital dengan $\mathrm{Vr}=30 \mathrm{k} \Omega$, dilakukan pengambilan data seperti dibawah ini :

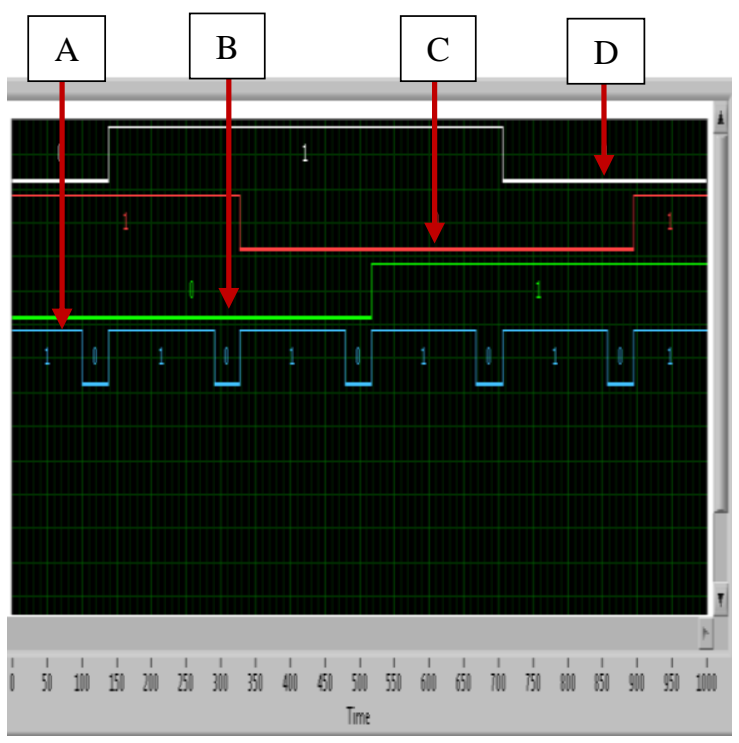


Gambar 4.1 Gelombang 3 fasa dengan $\mathrm{Vr}=30 \mathrm{k} \Omega$ menggunakan NI MyDAQ

Dari gambar gelombang diatas, hasil dari pengukuran dapat dijelaskan sebagai berikut

A. Menunjukan hasil gelombang dari sinyal pewaktu (clock)

B. Menunjukan hasil gelombang dari pembangkit sinyal $U$

C. Menunjukan hasil gelombang dari pembangkit sinyal $\mathrm{V}$

D. Menunjukan hasil gelombang dari pembangkit sinyal $\mathrm{W}$

$$
\begin{aligned}
T_{H} & =0,693(R a+R b) C \\
& =0,693\left(30 \times 10^{3}+10 \times 10^{3}\right)\left(10 \times 10^{-6}\right)= \\
& 277,2 \mathrm{mS}
\end{aligned}
$$$$
\mathrm{T}_{\mathrm{L}}=0,693 \mathrm{RbC}
$$$$
=0,693\left(10 \times 10^{3}\right)\left(10 \times 10^{-6}\right)=69,3 \mathrm{mS}
$$$$
\mathrm{T}=\mathrm{T}_{\text {high }}+\mathrm{T}_{\text {low }}=277,2+69,3=346,5 \mathrm{mS}
$$$$
f=\frac{1,44}{\left(R_{A}+2 R_{B}\right) C}=\frac{1,44}{500 \times 10^{-3}}=2,88 \mathrm{~Hz}
$$$$
D=\frac{T h}{T h+T l}=\frac{277,2}{277,2+69,3}=80 \%
$$

\section{Pengukuran pembangkit 3 fasa dengan $\mathrm{Vr}$} $=90 \mathrm{k} \Omega$

Pada pengukuran pembangkit 3 fasa secara digital dengan $\mathrm{Vr}=90 \mathrm{k} \Omega$, dilakukan pengambilan data seperti dibawah ini :
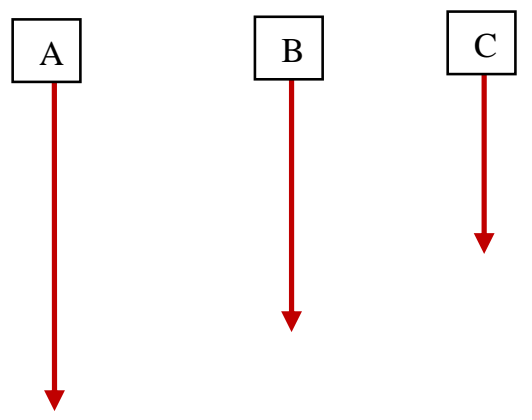

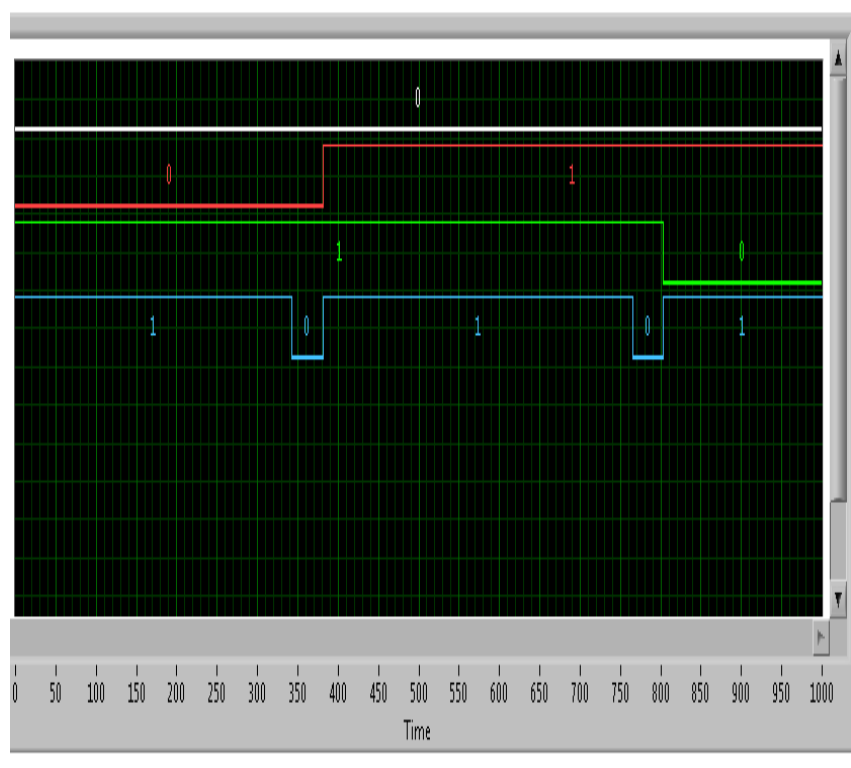

Gambar 4.2 Gelombang 3 fasa dengan $\mathrm{Vr}=90 \mathrm{k} \Omega$ menggunakan NI MyDAQ

Dari gambar gelombang diatas, hasil dari pengukuran dapat dijelaskan sebagai berikut

A. Menunjukan hasil gelombang dari sinyal pewaktu (clock)

B. Menunjukan hasil gelombang dari pembangkit sinyal $U$

C. Menunjukan hasil gelombang dari pembangkit sinyal $\mathrm{V}$

D. Menunjukan hasil gelombang dari pembangkit sinyal $\mathrm{W}$

$$
\begin{aligned}
T_{H} & =0,693(R a+R b) C \\
& =0,693\left(90 \times 10^{3}+10 \times 10^{3}\right)\left(10 \times 10^{-6}\right)=693
\end{aligned}
$$

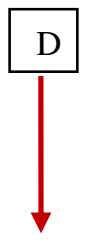

$$
\mathrm{mS}
$$

$\mathrm{T}_{\mathrm{L}}=0,693 \mathrm{RbC}$

$=0,693\left(10 \times 10^{3}\right)\left(10 \times 10^{-6}\right)=69,3 \mathrm{mS}$

$\mathrm{T}=\mathrm{T}_{\text {high }}+\mathrm{T}_{\text {low }}=693+69,3=762,3 \mathrm{mS}$

$f=\frac{1,44}{\left(R_{A}+2 R_{B}\right) C}=\frac{1,44}{1100 \times 10^{-3}}=1,3 \mathrm{~Hz}$ 


$$
D=\frac{T h}{T h+T l}=\frac{693}{693+69,3}=90 \%
$$

Dari semua pengujian pada perangkat pembangkit sinyal 3 fasa secara digital, dapat dilihat bahwa lebar gelombang pulsa pada keluaran rangkaian $D$ flip-flop sangat dipengaruhi oleh masukan sinyal pewaktu (clock) dalam hal ini rangkaian Multivibrator astabil.

Rangkaian pewaktu (clock) merupakan rangkaian Multivibrator astabil, adapun gelombang keluaran dari rangkaian ini sangat dipengaruhi oleh besarnya variabel resistor yang dioperasikan.

Satu Gelombang penuh dari keluaran pembangkit 3 fasa secara digital, didapatkan dari enam gelombang/enam periode keluaran sinyal pewaktu (clock).

\section{KESIMPULAN}

Berdasarkan penelitian berupa rangkaian pembangkit sinyal secara digital dapat disimpulkan hal-hal sebagai berikut :

1. Dalam penelitian atau eksperimen yang telah dilakukan, diperoleh bahwa gelombang sinyal 3 fasa muncul dari $D$ flip-flop yang ada pada rangkaian sinyal secara digital.

2. Lebar gelombang pada pembangkit sinyal 3 fasa dapat dipengaruhi dari pengaturan Vr yang ada pada rangkaian.
3. D-Flip-flop pada rangkaian pembangkit sinyal berfungsi sebagai Ring Counter, apabila salah satu masukan SET D-FF diaktifkan atau diberi logik "0", salah satu keluaran D-FF pasti berlogik "1" dan yang lain berlogik "0", serta keluaran yang berlogik "1" tersebut akan bergeser ke keluaran yang lain.

\section{UCAPAN TERIMAKASIH.}

Puji syukur saya ucapkan kepada Alloh yang maha esa atas selesainya penelitian ini, pada kesempatan ini penulis ingin mengucapkan terima kasih kepada:

1. Bapak DR.H.Dayat Hidayat, M.M selaku Rektor Universitas Pamulang.

2. Bapak IR.Dadang Kurnia, M.M selaku Dekan Fakultas Teknik Universitas Pamulang.

3. Bapak Syaiful Bakhri, S.T., M.Eng.Sc.,PhD. selaku Ketua Jurusan Teknik Elektro Universitas Pamulang.

4. Ibu Kartika Sekarsari, S.T., M.T.Selaku Dosen pembimbing I yang dengan sabar dan senantiasa membimbing dan menyarankan penulisan Tugas Akhir ini.

\section{DAFTAR REFERENSI}

[1] Andriani, Evi., 2010., sejarah dan definisi ic

http://eviandrianimosy.blogspot.com/201 0/05/sejarah-dan-definisi-ic.html. Diakses tanggal 2 desember 2013

[2] Mistory, Adi., 2012., struktur fungsi aplikasi dan cara kerja http://admistory.blogspot.com/2012/11/strukt ur-fungsi-aplikasi-dan-cara-kerja.html.

Diakses tanggal 2 desember 2013 
[3] Andililo, Mia., 2013 counter dan register http:/mia-andilolo.blogspot.com/2013/03/-

nter-dan-register.html. Diakses tanggal 2 desember 2013

[4] Dasar Elektronika, 2012, register geser ring counter http://elektronika-

dasar.web.id/2012/teori-elektronika/register-

geser-ring-counter/copyright (c) elektronoka dasar. Diakses tanggal 18 januari 2014

[5] Ibrahim KF. Teknik Digital. Andi Offset. Yogyakarta.1996. 